\title{
Reseña de GENAND, Stéphanie. (2018). Sade. París: Gallimard, Folio Biographies.
}

Desde que la obra del Marqués de Sade fue recuperada a comienzos del siglo XX, y a mediados del mismo despuntaron los estudios dieciochescos de la literatura francesa, se han escrito numerosos trabajos en torno su vida y trabajo literario. Entre ellos, la obra definitiva para los especialistas es la publicada en tres tomos, de 1986 a 1990, por Robert Laffont y escrita por Jean-Jacques Pauvert, quien años antes, junto a Annie Le Brun, editó los 14 tomos de las obras completas del polémico escritor. A la luz del voluminoso trabajo de Pauvert, cuya minuciosa e inédita investigación permitió desmontar los mitos en torno a Sade, más conocido por su reputación criminal que por su trabajo literario, se creería que cualquier otro texto con el mismo propósito resultaría repetitivo. Sin embargo, la reciente biografía escrita por Stéphanie Genand y publicada en 2018 dentro de la colección Biografías de Gallimard, aunque mucho más somera, presenta una visión distinta, humana y completamente necesaria de un escritor que aún genera polémica tanto en medios académicos como fuera de ellos.

Stéphanie Génand, profesora de la Universidad de Bourgogne, es especialista en literatura francesa del siglo XVIII: "Ses travaux portent sur les questions anthropologiques, les relations entre Lumières et passions, politique et moral, fiction et savoir, identité et altérité". Discípula de Michel Delon (referente obligado de la crítica y estudio del XVIII, editor de las obras completas de Sade en la Pléiade y autor de un texto biográfico cuya valiosa aportación consiste en el trabajo paleográfico de algunos manuscritos del Marqués [2007. Les vies de Sade. Paris: Éditions Textuel]), el conocimiento profundo de Genand sobre la literatura de Sade resalta en todas las páginas de esta nueva biografía, así como el enfoque relacionado con sus temas de estudio.

Para dar comienzo a su versión de la vida del escritor, Genand escoge una anécdota sucedida años después de la muerte de éste. Por razones que aún desconocemos, Sade especificó en su testamento que no se efectuara la disección de su cuerpo y que éste fuera enterrado hasta después de cuarenta y ocho horas en "la forêt de sa terre de Malmaison [aprés] une céremonie intime [et dans] une tombe invisible [afin que] nul n'en connaîtrait l'emplacement puisqu'il serait " semé dessus des glands » afin que toute trace de lui « disparaisse de dessus la surface de la terre »" (11). Como ejecutor de las disposiciones de su padre, el hijo menor de Sade 


\section{$126 \square$ RESEÑAS}

decidió no seguir las instrucciones del testamento y no sólo enterró el cuerpo en el cementerio de Charenton, sino que ordenó la celebración de una ceremonia presidida por un sacerdote. Aunque la instrucción de no diseccionar el cuerpo fue respetada en un principio, cuatro años después del deceso, debido a remodelaciones en el cementerio, numerosos cuerpos, entre ellos el de Sade, tuvieron que ser reacomodados. Con ese pretexto, un tal Doctor Ramon, quien fuera encargado de confirmar la muerte del célebre escritor, se presentó entusiasmado en el recinto ante la idea de por fin poder analizar el cuerpo. Un par de médicos alemanes acababan de publicar estudios muy aceptados entre la comunidad científica de la época en los que afirmaban que la fisiología, en particular las formas craneales, determinaban el carácter y algunas actitudes en los seres humanos (predisposiciones a la violencia, por ejemplo); el doctor Ramon estaba convencido de que la examinación del cráneo de Sade sería la prueba definitiva del origen de sus desviaciones sexuales y daría una explicación científica a los horrores de su escritura. Cuando el cráneo (actualmente conservado para su exhibición en el museo Flaubert de Historia y Medicina) estuvo a disposición del doctor, los análisis revelaron una estructura completamente común. "Son crâne était en tous points semblable à celui d'un père de l'Eglise" (11), concluyó el doctor, "Sade ne serait-il donc qu'un homme ?" (11), pregunta Genand al final de la anécdota.

La evocación del suceso post mortem posee la intención de humanizar un mito que continúa vivo. La estructura, organizada en tres actos y un entreacto, busca, también, romper con la idea general de que Sade sólo se dedicó a escribir catálogos de tortura aderezados con pornografía y recordar que su mayor pasión escritural fue el teatro. A lo largo del libro, Genand se esfuerza por hacer ver a sus lectores que, lejos de la leyenda que ha trascendido, Donatien Alphonse François de Sade (a quien sus padres quisieron nombrar Aldonze, pero terminó siendo llamado Alphonse por un error de transcripción en su registro de nacimiento), fue un hombre contradictorio, dramaturgo apasionado, amante del humor negro, víctima de la política inhumana del encierro en el Antiguo Régimen, víctima también de una serie de desafortunadas casualidades que contribuyeron a crearle una fama criminal que terminó por deshumanizarlo hasta convertirlo en concepto: sadismo. Desde la perspectiva de Genand, la confusión en la escritura de su nombre, la exhumación del cuerpo, el entierro en Charenton y la conservación del cráneo para exhibición pública son rasgos simbólicos de una vida cuyo destino estuvo siempre a merced de las decisiones de otros.

El primer acto de la biografía, titulado "Libre", abarca los años de infancia y juventud del autor, su posterior matrimonio con Renée-Pélagie y el recuento de los tres escándalos que desembocaron en un encierro de trece años, primero en La Bastilla y después en el Castillo de Vincennes. En esta etapa los lectores se encuentran con un Donatien bien parecido, melancólico, popular en su entorno social y dado al ambiente banal de las fiestas de la nobleza y los artistas teatrales; algo muy distinto de la personalidad retadora y aislada que permanece en el imaginario de 
nuestra época. Precisamente por ello, Genand decide referirse a él como Donatien, para marcar una diferencia entre en la vida privada, que ha quedado en el olvido, y la figura pública, mítica, que conocemos. No es sino a partir de la sucesión de escándalos que le forjaron fama de libertino, y cuyos detalles dejo para el lector curioso, que la autora comienza a utilizar el nombre Sade. Es notorio también que, a partir de una minuciosa lectura de la correspondencia entre familiares del autor y del autor mismo, Genand reinterpreta las relaciones de éste con su esposa y la familia de ésta.

Tanto en este primer acto, como en los subsecuentes, Genand no sólo se limita a narrar con un excelente estilo la vida del joven aristócrata, también resalta la intención lúdica de su escritura, así como la conexión entre ésta y algunos episodios de su vida, en particular, los escándalos, los viajes y el encierro. Dicho aspecto sobresale desde las primeras obras del Marqués:

une pièce de théâtre, Le Philosophe soit-disant, et deux récits de voyage, en Hollande et en Italie [où] le choix de la comédie, ainsi placée au frontispice du corps sadien, souligne la légèreté native de son imaginaire [...] Ces écrits de jeunesse livrent en outre de précieux indices sur la manière dont Sade conçoit le métier d'homme de lettres : de la pièce de théâtre, destinée à la représentation, aux voyages eux aussi adressés sur la forme de lettres, à une comtesse fictive, son écriture a toujours besoin d'un destinataire. (51-52)

En este tipo de comentarios reside el verdadero aporte del texto de Genand a los estudios sadeanos. Como estudiosa de la literatura del siglo XVIII, la autora establece relaciones intrínsecas entre las reflexiones del autor (registradas en cuadernos de notas y catálogos que sobreviven hasta nuestros días), derivadas de su propia experiencia de vida, y su concepción de la literatura y del trabajo escritural. A través de la mirada de Genand, vemos a Sade viajar por Italia para escapar de la guillotina (a la cual fue sentenciado y posteriormente ejecutado de manera simbólica en una plaza pública) y fascinarse por las costumbres "singulares" de los lugares que visitó, material que posteriormente utilizaría en sus voluminosas obras: "Plus que la beauté, c'est en effet l'écart, le bizarre ou le piquant qui attirent son attention $[\ldots]$ Donatien trouve dans la diversité du monde la matière d'une réflexion philosophique sur l'homme et les peuples. Cette démarche explique le choix précoce sous sa plume du modèle de la 'dissertation'” (95).

La relación entre vida y obra se vuelve más evidente a partir del segundo acto, "Enfermé", donde la autora relata la experiencia inhumana del encierro de 13 años. Durante su estancia en la Bastilla y Vincennes, Sade experimentó la sinrazón carcelaria y la deshumanización del preso apartado de la sociedad. Al igual que otros críticos que han hablado de la somatización del dolor del encierro (Lucienne Frappier-Mazur, por ejemplo), Genand toca el tema de la gordura exponencial del Marqués, sucedida en esa época, como un síntoma de su sufrimiento. Sin 
embargo, más allá de la postura psicoanalítica, a través de las solicitudes que el preso hacía a su esposa, Genand pone en evidencia un componente emocional antes no mencionado y que resulta fascinante para los lectores y estudiosos del escritor. En el imaginario del autor, la Provenza es un lugar idílico, es emblema de una infancia feliz al lado del tío filólogo que le enseñó el amor a las letras y la importancia del linaje Sade, emparentado con Laura de Noves, musa de Petrarca. La comida de la Provenza, en especial los postres, cuyas frutas frescas remiten a la campiña francesa, se vuelve en la prisión el recuerdo de ese entorno idílico de libertad y aprendizaje. Así, de acuerdo con Genand, uno de los pasatiempos de Sade en el encierro, además de la glotonería, es escribir listas de postres y dulces que solicita le sean llevados para después emitir críticas acerca de la autenticidad de las recetas. En esas listas interminables, Genand observa primero un rasgo característico de la escritura sadeana, la obsesión por enlistar las cosas del mundo, y segundo, la lógica imperante dentro de la prisión. El cuerpo encerrado de Sade, imagina y se aleja de la realidad del hacer y del vivir a través de la comida que lo transporta a la libertad de la Provenza. En ese encierro, la vida está basada en castigos (de los cuales experimentó muchos, como la privación de la luz solar por grandes periodos) y recompensas, al igual que en las novelas pertenecientes a su obra publicada de manera anónima (textos pornográficos).

El fin de la Revolución otorgó la libertad a Sade. Durante un breve periodo, un Entreacto, el otrora marqués, ahora ciudadano, volcó su creatividad en el teatro. Para Genand existe una diferencia entre la obra pre y post encierro: si antes de la Bastilla Sade era capaz de crear comedias ligeras, después, su teatro se vuelve sombrío y analítico de una humanidad atroz. Las obras que intenta colocar en teatros no tienen éxito y, finalmente, se decide por la narrativa sórdida. Justine, Juliette y La philosophie dans le boudoir fueron publicadas en el anonimato y nunca reconocidas en vida por el autor, aunque tales precauciones no fueron suficientes y de nuevo terminó encarcelado.

En el tercer acto, Aliéné, Genand narra los últimos años de vida. De nuevo en el encierro, pero esta vez del manicomio, Sade se enfrenta primero a una libertad parcial y cómoda gracias al director del recinto. Ahí, el autor escribe y monta obras especialmente pensadas para ayudar en los procesos de recuperación de los enfermos, mismas que, especifica Genand, desafortunadamente no han sido recuperadas (dado que a lo largo de los años se han encontrado numerosos manuscritos, la autora no pierde la esperanza de que dichas obras salgan a la luz en algún momento). El periodo de bonanza en medio de la locura es breve, pues al final de su vida Sade se enfrenta a la ignominia de un expediente médico falso que lo cataloga como un hombre incorregible "dans un état perpétuel de démence libertine" (28990). Así, el caso Sade se vuelve emblema de represión tanto del antiguo como del nuevo régimen: 
Son internement à Charenton illustre donc la persistance, en France, d'un inquiétant arbitraire au lendemain de la Révolution : pendant que se promulgue le Code civil, qui définit les droits et les devoirs des citoyens, la justice, profitant d'un angle mort juridique, orchestre impitoyablement la disparition des opposants, dont l'asile devient la tombe et l'accusation de folie le passeport pour l'oubli. (290)

Las circunstancias particulares de los encierros de Sade ponen en evidencia la doble moral de la sociedad francesa antes y después de la Revolución. Acusado primero de libertinaje, el autor termina su vida bajo el estigma de la locura debido a una escritura desafiante que expone los vicios humanos mediante una visión maniquea del mundo, obtenida en el encierro que supuestamente estaba destinado a corregirlo. Ni el absolutismo de la monarquía, ni la censura del Terror, ni la democracia de la República encontraron un lugar para Sade.

A través de esta nueva biografía, Genand construye un perfil distinto con rasgos de una modernidad aterradora. Lejos del mito y a partir de una investigación minuciosa de documentos personales y correspondencia, Sade se construye aquí como un hombre desafortunado y criminalizado, pero también, de acuerdo con la autora, como un valioso escritor cuya obra debe ser releída y repensada.

Berenice ORTEGA VILLELA

Facultad de Filosofía y Letras

Universidad Nacional AutónOma DE MÉXICO

México 